\title{
High-Quality RNA and DNA from Flow Cytometrically Sorted Human Epithelial Cells and Tissues
}

BioTechniques 32:888-896 (April 2002)

\author{
M.T. Barrett ${ }^{1}$, J. Glogovac ${ }^{1}$, \\ L.J. Prevo1, B.J. Reid ${ }^{1,2}$, \\ P. Porter ${ }^{1}$, and \\ P.S. Rabinovitch ${ }^{1,2}$ \\ ${ }^{1}$ Fred Hutchinson Cancer \\ Research Center, and \\ ${ }^{2}$ University of Washington, \\ Seattle, WA, USA
}

\section{INTRODUCTION}

Accurate genotyping and expression analyses of neoplastic progression require the isolation of subpopulations of cells from a heterogeneous background of multiple cell types present in a given tissue $(3,5,9)$. Recent developments in array technologies have created the potential for both comprehensive expression analysis and genotyping in human neoplasia (11). However, a limitation of gene expression technologies is the requirement for relatively large amounts of high-quality RNA from purified cell populations. Recent technological improvements make it possible to obtain high-quality nucleic acids from solid tissues by microdissection (9). In particular, laser capture microdissection (LCM) allows the isolation of relatively pure cell populations. However, the yields from microdissection are limited by the labor involved, especially when neoplastic cells are intimately admixed with benign stroma and/or inflammatory cells. Furthermore, specimens from human tissues can contain multiple cell populations with different DNA ploidies that have different genetic abnormalities (1) and for which separate expression analysis would be ideal.

We have previously used flow cytometry to evaluate and to purify neoplastic epithelial cells from gastrointestinal biopsies $(1,6,13)$. These techniques have relied on the preparation of nuclei and staining with DNA dyes and antibodies to nuclear antigens. The analysis of DNA content combined with appropriate antibodies in multiparameter flow cytometry allows neoplas- tic epithelial cells to be identified and purified from a background of heterogeneous cell types. The use of sorted cells permits the accurate and comprehensive genotyping of the cell populations of interest $(1,6,13)$. However, similar purification methods have not been adapted to isolate intact cells suitable for RNA analysis.

Several reports have shown that intact RNA can be recovered from cells flow-sorted after labeling of cytoplasmic epithelial cell-specific cytokeratins $(2,4,7,8)$. Whole-cell sorting typically involves treating cells in organic fixatives, followed by staining with tissuespecific antibodies in an aqueous solution. Although cytoplasmic RNA can be obtained with these methods, these techniques are limited by the need for extensive precautions against RNase activity and the rapid loss of RNA in the post-fixation aqueous solutions. To increase the efficiency of whole-cell purification and RNA recovery from epithelial cells and biopsy samples, we have developed a flow sorting protocol using a commercially available reagent, RNAlater $^{\mathrm{TM}}$ (Ambion, Austin, TX, USA), which allows the preservation of RNA during fixation, immunofluorescent cytokeratin labeling, and subsequent sorting of whole cells.

\section{MATERIALS AND METHODS}

\section{Cell Line and Tissue Samples}

A549 lung adenocarcinoma cells were cultured in RPMI media supplemented with 5\% FCS. Cells were 
trypsinized according to standard protocols and then either fixed in $95 \%$ ethanol $/ 5 \%$ acetic acid for $10 \mathrm{~min}$ at $4^{\circ} \mathrm{C}$, followed by resuspension in PBS with 1\% BSA (Sigma, St. Louis, MO, USA) (PBA) or resuspended in RNAlater and kept on ice. Breast tissues were obtained from mastectomy and biopsy specimens from the University of Washington Tissue Bank, a resource that has been approved by the institutional review board.

Single-cell suspensions were created to evaluate RNA retrieval from flowsorted samples. Breast tumor tissue from a radical mastectomy was divided and processed in parallel using one of the three following methods. ( $i$ ) The sample was frozen in MEM (Invitrogen, Carlsbad, CA, USA) containing $10 \%$ DMSO (Fisher, Fair Lawn, NJ, USA) and then thawed on ice, placed in PBA, and minced. The minced tissue was resuspended in PBA, filtered through $40 \mu \mathrm{m}$ mesh, and centrifuged. The supernatant was decanted, and cell pellets were resuspended in $100 \mu \mathrm{L}$ RNAlater. (ii) A second portion of the same breast tissue was placed directly into RNAlater and held at $2{ }^{\circ} \mathrm{C}$ for up to two weeks in the refrigerator. (iii) A third portion was placed into a $1: 1$ dilution of RNAlater and stored at $2^{\circ} \mathrm{C}$. For the second and third methods, the tissue samples were removed from RNAlater, minced in PBA, and filtered through 40 $\mu \mathrm{m}$ mesh. The cell suspensions from all of the techniques were then diluted with 4 volumes of PBS to allow the cells to pellet before centrifugation. The supernatant was decanted, and the cell pellets were resuspended in $100 \mu \mathrm{L}$ PBA.

\section{Cell Sorting}

The A549 cell suspensions in RNAlater or PBA were incubated with either $10 \mu \mathrm{L}$ epithelial-specific cytokeratin CAM 5.2-FITC (BD Biosciences, San Jose, CA, USA) or a FITC-labeled, isotype-matched mouse immunoglobulin IgG2a-FITC (BD Biosciences) on ice for $1 \mathrm{~h}$. The cell suspensions from breast tissues were incubated on ice for $1 \mathrm{~h}$ with $6 \mu \mathrm{L} \mathrm{AE} 1 / \mathrm{AE} 3 \mathrm{PE}$ (Roche Applied Science, Indianapolis, IN, USA), which recognizes a wider variety of acidic and basic cytokeratins than CAM 5.2. In all cases, the samples were dilut- ed with $1.5 \mathrm{~mL}$ PBA and then centrifuged. Supernatants were decanted, and the cell pellets were resuspended in 0.5-1.0 mL $10 \mu \mathrm{g} / \mathrm{mL} \mathrm{2,4} \mathrm{diamidino-6-}$ phenylindole (DAPI) in NST buffer (146 mM NaCl, 10 mM Tris-HCl, pH 7.4, $0.1 \%$ Nonidet $^{\mathrm{TM}} \mathrm{P}-40,2 \mathrm{mM} \mathrm{Ca}$, $20 \mathrm{mM} \mathrm{Mg}$, and $0.05 \%$ BSA). All centrifugation steps were performed at $4 \times$ $g$ for $8 \mathrm{~min}$ at $2^{\circ} \mathrm{C}$, and all reagents were free of DNase and RNase.

Whole cells were sorted by DNA content and cytokeratin staining on a Vantage $^{\mathrm{TM}}$ flow cytometer (BD Biosciences), with $100 \mathrm{~mW}$ and $488 \mathrm{~nm}$ excitation (FITC and PI) and $100 \mathrm{~mW}$, 354-361 nm (UV) excitation (DAPI). The instrument was aligned daily using "DNA check" beads (Beckman Coulter, Miami, FL, USA) to give CVs of less than $3 \%$. For some experiments, RNase contamination of the cell sorter was reduced by autoclaving tubing and diethyl pyrocarbonate (DEPC) treating sheath fluid before sorting. List-mode data were analyzed using MultiCycle $\mathrm{AV}^{\mathrm{TM}}$ and MultiPlus ${ }^{\mathrm{TM}}$ software (Phoenix Flow Systems, San Diego, CA, USA). Negative controls were used to establish the level of nonspecific fluorescence staining associated with the cells.

\section{RNA/DNA Extraction}

RNA was extracted according to one of two protocols. When RNA and genomic DNA were simultaneously extracted, we used Totally RNA ${ }^{\mathrm{TM}}$ (Ambion) according to the supplier's instructions. Genomic DNA was extracted from pooled organic phases for each RNA sample. Briefly, the pooled organic phases were mixed with an equal volume of extraction buffer $(0.1$ $\mathrm{M} \mathrm{NaCl}, 10$ mM Tris-HCl, pH 8.0, 1 $\mathrm{mM}$ EDTA, $1 \%$ SDS) that was adjusted to $\mathrm{pH} 12.0$ with $5 \mathrm{M} \mathrm{NaOH}$ immediately before use. The samples were shaken, placed on ice for $10 \mathrm{~min}$, and then centrifuged at $4^{\circ} \mathrm{C}$ for $20 \mathrm{~min}$ at $10000 \times g$. DNA was recovered by precipitation with $7.5 \mathrm{M}$ ammonium acetate/ethanol precipitation. In all other cases, each sample was processed with a Qiashredder ${ }^{\mathrm{TM}}$ before RNA extraction with an RNeasy ${ }^{\circledR}$ Mini kit (Qiagen, Valencia, CA, USA). RNA was resuspended in RNase-free water and quantitated by SYBR ${ }^{\circledR}$ Green II (Molecular
Probes, Eugene, OR, USA) staining and fluorescence (530 $\mathrm{nm}$ excitation, $485 \mathrm{~nm}$ emission) with a Cytofluor ${ }^{\mathrm{TM}}$ reader (PerSeptive Biosystems, Framingham, MA, USA).

\section{Real-Time PCR (TaqMan) Assays}

To assess the integrity of the RNA, we measured the relative $3^{\prime}$ and $5^{\prime}$ levels of the transcript for glyceraldehyde-3phosphate dehydrogenase (GAPDH). One microliter of each RNA preparation was used for single-tube reactions with rTth DNA polymerase using the TaqMan ${ }^{\circledR}$ EZ RT-PCR Kit (Applied Biosystems, Foster City, CA, USA). The amplifications for each primer and probe set were performed in separate reactions. The concentration thresholds $\left(C_{t}\right)$ for the detection of the $3^{\prime}$ and the $5^{\prime}$ regions of the GAPDH transcript were used to assess the quality of RNA in each of the samples. $C_{t}$ values increase with a decrease in RNA template concentration. Therefore, to assess RNA integrity on a scale from 0 (low $3^{\prime}$ levels relative to $5^{\prime}$ levels) to 1 (intact RNA), we used the ratio $C_{t}\left(3^{\prime}\right) / C_{t}\left(5^{\prime}\right)$. Serial dilutions $(50 \mathrm{ng} / \mu \mathrm{L}$ to $50 \mathrm{pg} / \mu \mathrm{L})$ of RNA from unsorted fresh A549 cells were used as controls for all of the experiments. Fluorescence was monitored in real time using an ABI PRISM ${ }^{\circledR} 7700$ detection system (Applied Biosystems). Primers and probe for the GAPDH 5'specific assay were supplied in the GAPDH Control Reagent Kit (Applied Biosystems). The product is 226 bases and spans intron 3. The primers and probe for the GAPDH $3^{\prime}$ assay were forward primer $\left(5^{\prime}\right.$-TCCACCTTTGACGCTGG-3'), probe (5'-CTGGCATTGCCCTCAACGACCACT- $3^{\prime}$ ), and reverse primer $\left(5^{\prime}\right.$-TCATACCTAGGAAATGAGCTTGACA-3'). The product is 71 bases, includes regions of exons 7 and 8, and spans intron 8. Agarose gels were used to validate $C_{t}$ ratios as a measure of RNA integrity. The primers and probe used to measure the levels of telomerase (hTERT) were forward primer (5'-TGTACTTTGTCGTGGATGTGACG-3'), probe (5'-CGCGTACGACACCATCCCCCA-3'), and reverse primer (5'-TGACCTCCGTGAGCCTGTC-3'). The hTERT product is 65 bases, includes regions of exons 5 and 6 , and spans intron 6 . Thermal cycling 
conditions for all reactions were at $50^{\circ} \mathrm{C}$ for a 2-min hold, $60^{\circ} \mathrm{C}$ for $30 \mathrm{~min}$ reverse transcription, $95^{\circ} \mathrm{C}$ for $5 \mathrm{~min}$ deactivation, followed by 40 cycles at $94^{\circ} \mathrm{C}$ for $20 \mathrm{~s}$ denaturation, and $62^{\circ} \mathrm{C}$ for a 1-min annealing/extension step. The primers and probes for the GAPDH $3^{\prime}$ and the hTERT-specific assays were designed using Primer Express ${ }^{\mathrm{TM}}$ software (Applied Biosystems).

\section{Genotyping and Sequencing}

Whole genome amplification was performed according to previously published protocols (12). Briefly, aliquots of DNA were randomly amplified using a mixture of degenerate 15 -mer to prime the reaction in a $600-\mu \mathrm{L}$ volume. Aliquots from each reaction were then used for subsequent locus-specific PCR with polymorphic markers D9S930, D9S935, and D9S932. We used a nested PCR strategy for amplifying and sequencing TP53 from genomic DNA. Exons 5-9 were initially amplified with one set of primers (forward, 5'-CGTGTTCCAGTTGCTTTATC-3', and reverse, 5'-GGAGGGCCACTGACAACCA- $3^{\prime}$ ) and then used as a template for the amplification of exons 5 and 6 (forward, 5'-GGAGGGCCACTGACAACCA-3', and reverse, 5'-GGAGGGCCACTGACAACCA-3'), according to our published protocols (13). All of the samples were sequenced by automated sequencing with fluorescently labeled chain-terminating ddNTPs and Taq DNA polymerase, according to the supplier's specifications (Applied Biosystems). The products were analyzed on an ABI PRISM 377 Automated DNA Sequencing machine (Applied Biosystems). All reactions were done with PTC-200 ${ }^{\mathrm{TM}}$ thermal cyclers (MJ Research, Cambridge, MA, USA).

\section{RESULTS}

\section{Flow Cytometry}

Cytokeratin labeling. The A549 cells prepared by standard ethanol/ acetic acid fixation showed strong staining with CAM 5.2 (Figure 1A). We repeated the staining and sorting protocols using cells that had been fixed and stained in RNAlater (Figure
1C). Cytokeratin-positive cells could be clearly differentiated by cytometry after being prepared and stored in this reagent (Figure 1C).

Single-cell suspensions from breast tissue were prepared from one of these samples by slowly thawing frozen tissue and then mincing on ice in PBA. The cells were resuspended in RNAlater and then held at $4^{\circ} \mathrm{C}$ from $30 \mathrm{~min}$ to $1 \mathrm{~h}$ before staining with DAPI. Cytokeratin staining was observed for the fixed cells, illustrating the preserved cytokeratin and DAPI fluorescence seen in solid tissue (data not shown). A second sample was fixed in RNAlater for two weeks before

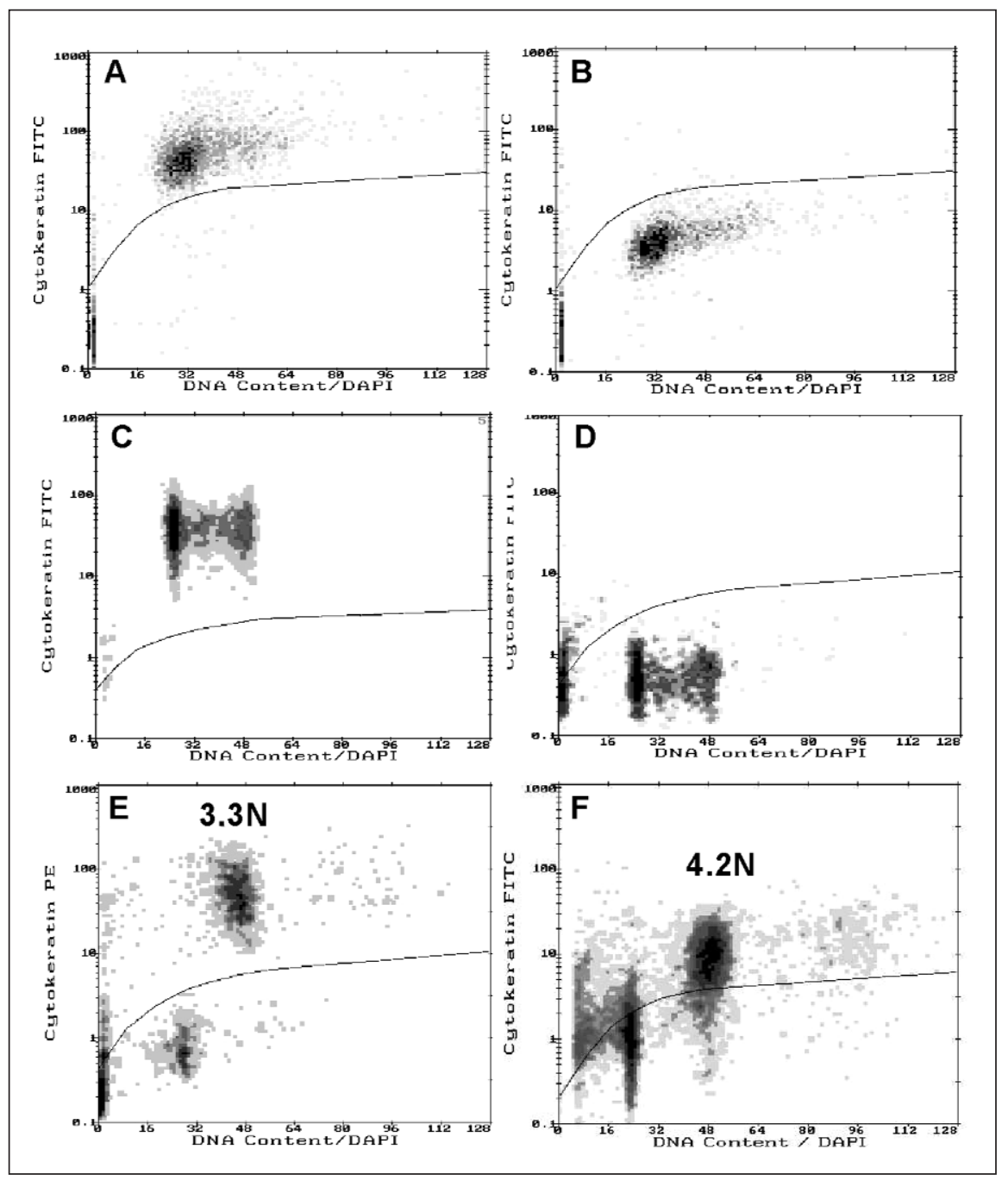

Figure 1. DAPI DNA versus cytokeratin FITC cytograms of A549 cells and breast tumor tissue. Whole cells were sorted by DNA content and cytokeratin staining on a Vantage flow cytometer, with 100 $\mathrm{mW}, 488 \mathrm{~nm}$ excitation (FITC and PI), and $100 \mathrm{~mW}, 354-361 \mathrm{~nm}$ (UV) excitation (DAPI). (A) A549 cells fixed in ethanol/acetic acid. (C) A549 cells held in RNAlater for two weeks. (E) Cytokeratin-positive aneuploid $(3.3 \mathrm{~N})$ cell population detected in breast tumor tissue held in RNAlater for two weeks. $(\mathrm{F})$ Cytokeratin-postive $2 \mathrm{~N}$ and $4.2 \mathrm{~N}$ cell populations in breast tumor tissue held in RNAlater for two weeks. Panels B and D are isotype-matched controls for panels A and C, respectively. 
Table 1. RNA Yields and GAPDH $3^{\prime} / 5^{\prime} C_{t}$ Ratios of Samples Processed and Sorted by Different Methods

\begin{tabular}{|lcc|}
\hline Sample $(\boldsymbol{n})$ & $\begin{array}{c}\text { RNA Yielda } \\
\mu \mathbf{g} / \mathbf{1 0}^{6} \text { Cells } \\
\overline{\mathbf{x}} \pm \mathrm{SD}\end{array}$ & $\begin{array}{c}\text { GAPDH } \\
\mathbf{3}^{\prime} / \mathbf{5}^{\prime} \mathbf{C}_{\mathbf{t}} \text { Ratio } \\
\overline{\mathbf{x}} \pm \text { SD }\end{array}$ \\
\hline Control RNA 0.5 ng (5) & - & $0.98 \pm 0.08$ \\
A549 Ethanol Fix (3) & $5.8 \pm 1.0$ & $0.95 \pm 0.03$ \\
A549: Ethanol Fix/Sorted (5) & $5.8 \pm 1.6$ & $0.77 \pm 0.09$ \\
A549: Ethanol Fix/Sorted-DEPC (2) & $5.2 \pm 0.6$ & $0.61 \pm 0.1$ \\
A549: Ethanol/Two weeks at -20 ${ }^{\circ} \mathrm{C}(5)$ & $5.1 \pm 0.6$ & $1.02 \pm 0.02$ \\
A549: RNAlater (3) & $5.7 \pm 0.8$ & $1.06 \pm 0.07$ \\
A549: RNAlater/Sorted (6) & $5.3 \pm 1.7$ & $1.06 \pm 0.04$ \\
A549: RNAlater/Two weeks at -20 ${ }^{\circ} \mathrm{C}(4)$ & $5.7 \pm 0.1$ & $0.99 \pm 0.04$ \\
Primary Breast: RNAlater/Sorted (7) & $8.5 \pm 3.3$ & $1.01 \pm 0.11$ \\
$n$, number of preparations & & \\
ayield determined by spectrofluorometry & & \\
\hline
\end{tabular}

RNA yields. The amount of total RNA obtained from unsorted A549 cells fixed in either ethanol/acetic acid or RNAlater was typically between 5 and $6 \mu \mathrm{g} / 10^{6}$ cells (Table 1). RNA yields from the A549 cells that were fixed, stained, and sorted were comparable to unsorted controls. However, typical RNA yields from fresh, frozen tissue processed in RNAlater were more variable $(8.5 \pm 3.3 \mu \mathrm{g}$ total $\mathrm{RNA} /$ $10^{6}$ sorted cells). The number of single cells (rather than aggregates) obtained from biopsy material was variable and affected the overall RNA yields from each tissue after sorting. RNA yields and quality remained stable in the samples held in RNAlater at $-20^{\circ} \mathrm{C}$ for more than two weeks.

\section{Gel Analysis of RNA}

To assess the quality of RNA from the different cell preparations, we ran aliquots on $1 \%$ agarose gels stained with ethidium bromide. The $28 \mathrm{~S}$ and $18 \mathrm{~S}$ bands were used to determine the quality of RNA in each of the samples. Controls (non-sorted) for ethanol/acetic acid- and RNAlater-fixed samples

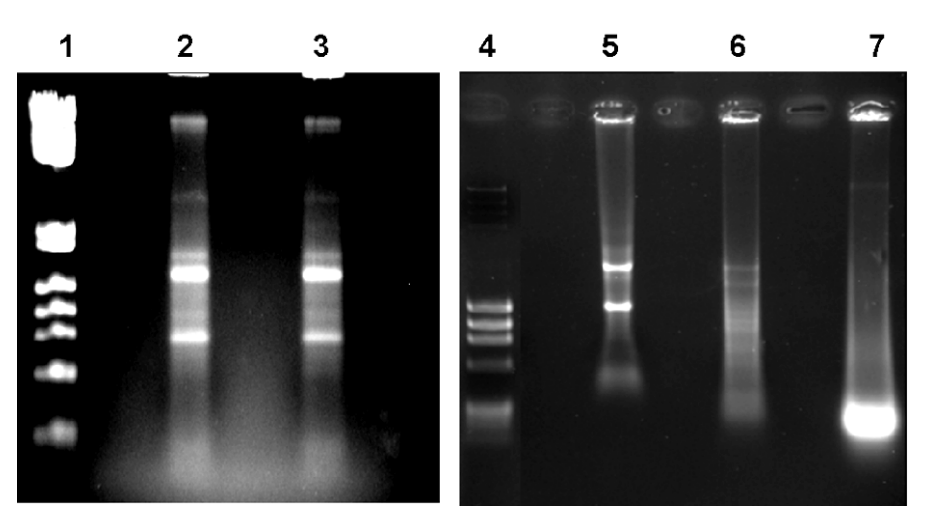

Figure 2. Gel electrophoresis analysis of RNA from whole-cell sorted samples. A549 cells were prepared by standard tissue culture techniques, washed in PBS, and then resuspended in either RNAlater or 95\% ethanol/5\% acetic acid before staining and sorting. Total RNA was isolated by acid phenol:chloroform extraction. Aliquots of each sample were mixed in a ratio of $1: 1$ with loading dye and then run on a $1 \%$ agarose gel stained with ethidium bromide. Lane 1, ФX DNA size marker; lane 2, RNAlater + DEPC; lane 3, RNAlater-DEPC; lane 4, 1-kb DNA size marker (Invitrogen, Carlsbad, CA, USA); lane 5, ethanol/acetic acid no-sort control; lane 6, ethanol/acetic acid sorted + DEPC; and lane 7, ethanol/acetic sorted - DEPC.

showed strong $28 \mathrm{~S}$ and $18 \mathrm{~S}$ bands that are typical of intact total RNA (data not shown). RNA from samples prepared in RNAlater remained intact even after the cells had been stored for one week at $-20^{\circ} \mathrm{C}$ before extraction (Figure 2, lane 2 ). Furthermore, RNA quality was not affected by the absence of precautions to reduce RNase activity (Figure 2, lane $3)$. In contrast, RNA from the cells fixed in ethanol/acetic acid showed extensive degradation, even in the presence of the DEPC treatment of the sorting apparatus (Figure 2, lanes 5-7).

\section{Real-Time PCR (TaqMan)}

The sorted samples that had been fixed in RNAlater retained high $\mathrm{C}_{\mathrm{t}}$ ratios for GAPDH, with or without the treatment of the cell sorter by autoclaving tubing and DEPC treating solutions (Table 1). Cells fixed in ethanol and subsequently sorted by cytokeratin positivity had reduced $\mathrm{C}_{\mathrm{t}}$ ratios, which is consistent with RNA degradation detected by gel analysis, regardless of whether RNase precautions were employed.

We repeated these assays with the flow-sorted breast epithelial cells. The samples prepared in RNAlater retained high $3^{\prime} / 5^{\prime} \mathrm{C}_{\mathrm{t}}$ ratios for GAPDH. To further assess the RNA from flow-sorted cells, we measured hTERT in a series of samples, including the breast tumor sample with a GAPDH $\mathrm{C}_{\mathrm{t}}$ ratio of 1.01 (Figure 3 and Table 1). GAPDH levels in breast and A549 cells (mean $\mathrm{C}_{t}, 24.8$ and 16.7 , respectively) were used as a measure of the RNA present in each sample that had been assayed. Relatively high levels of hTERT were detected in the flow-sorted breast epithelial cells (mean $\mathrm{C}_{t}, 28.5$ cycles) compared to A549 cells (mean $C_{t}, 32.5$ cycles).

\section{Sequencing and Genotyping}

DNA extracted from the organic phases of the RNA isolations was used as a template for sequencing reactions, whole-genome amplification, and locus-specific PCR. Full-length sequences for exons 5 and 6 of TP53 (469 bp) were obtained from both ethanol/ acetic acid- and RNAlater-fixed and sorted samples, using primers nested within a 1.8-kb initial PCR product spanning exons 5-9. Figure 4 shows an 
example from sorted RNAlater-fixed breast cells. A $\mathrm{G} \rightarrow \mathrm{A}-5$ splice acceptor site somatic mutation in exon 5 is clearly demonstrated in the epithelial cells sorted from this breast carcinoma biopsy. We also obtained PCR products from the same samples using either genomic or whole-genome amplified DNA as a template for polymorphic microsatellite markers (data not shown).

\section{DISCUSSION}

RNAlater is an aqueous reagent recommended for tissue storage and RNA stabilization. Our results with both A549 cells and fresh, frozen breast biopsy material show that epithelial tissues processed in this reagent are suitable for cytokeratin immunolabeling and flow sorting (Figure 1, A-F). The use of an aqueous reagent for fixation eliminates the need to wash permeabilized cells before sorting, thus increasing the efficiency of RNA recovery from whole-cell sorted samples. In addition, the sorting of RNAlater-treated cells can be performed in the absence of the extensive RNase precautions that are required for cells resuspended in routine aqueous buffers.

Flow cytometric sorting requires single-cell suspensions. In our preliminary studies, optimal conditions for preparing single-cell suspensions for flow sorting involved thawing fresh frozen tissue and rapid mincing on ice in PBA, followed by resuspension and staining in RNAlater. Tissues stored directly in RNAlater were more resistant to single-cell preparation than fresh tissues, just as are tissues fixed in ethanol or ethanol/acetic acid. Therefore, processing the tissues before resuspension in RNAlater may be optimal for the efficient preparation of single-cell suspensions. This requirement may limit the usefulness of our method for some nuclease-rich tissues. Preliminary observations suggest that the efficiency of preparing single-cell suspensions may be enhanced, without compromising the quality of RNA obtained when solid tissues are fixed in diluted $(50 \%)$ RNAlater (Figure 1F).

Visual inspection by gel electrophoresis allows the analysis of RNA yield and quality, but the amount of ma- terial obtained from biopsies of interest can limit the use of this analysis. To avoid the loss of material for gel analysis, we used a real-time PCR (TaqMan) assay to measure the relative quality of RNA. High $\mathrm{C}_{\mathrm{t}}$ ratios for GAPDH were indicative of intact RNA and were consistently obtained from cell lines and fresh, frozen tissues prepared in RNAlater. Furthermore, these samples provided high-quality material for both expression analysis (Figure 3 ) and se-

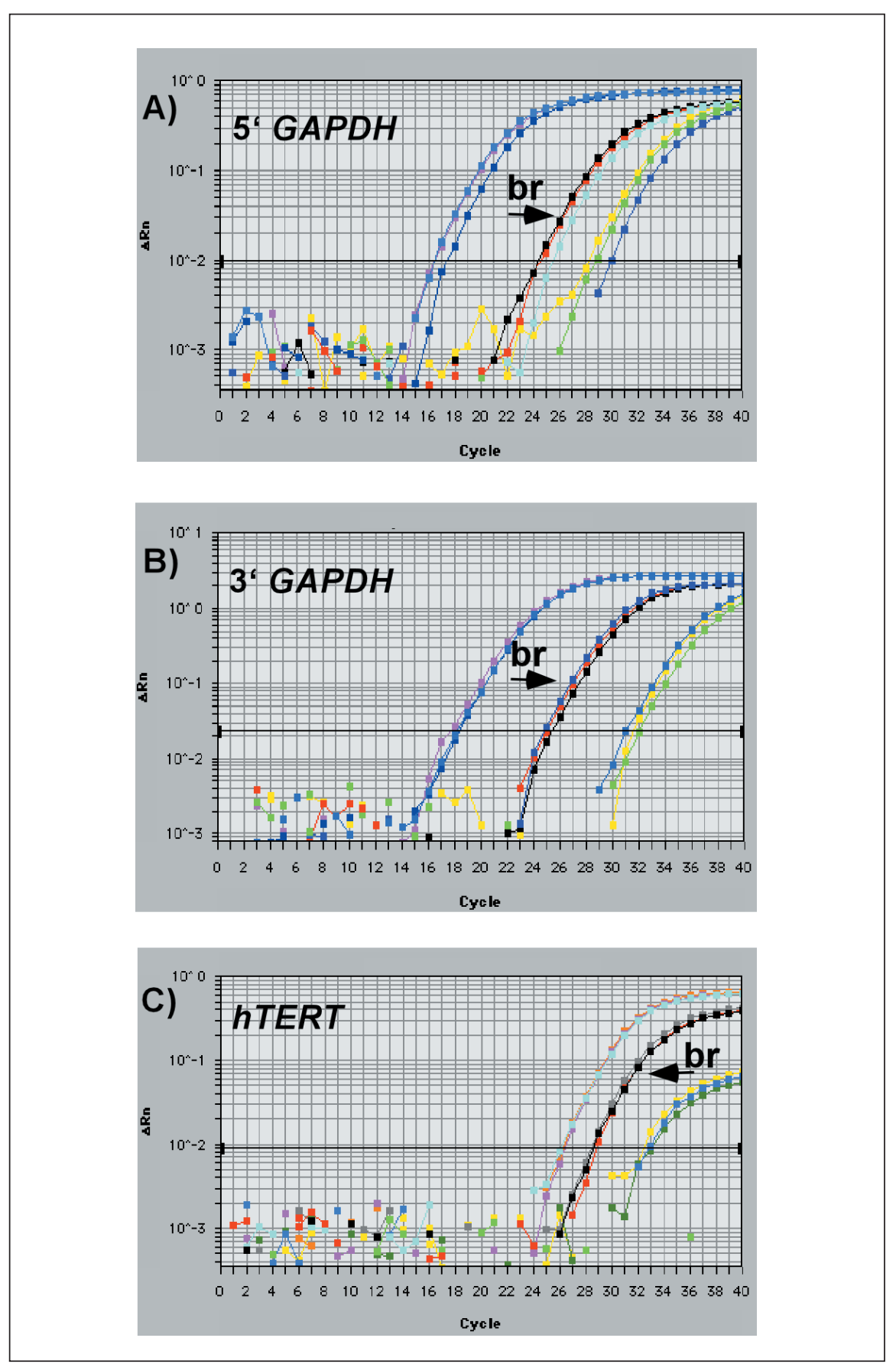

Figure 3. Real-time PCR (TaqMan) analysis of RNA from whole-cell sorted cytokeratin-positive breast epithelial cells. (A) GAPDH, (B) 3' GAPDH, and (C) hTERT. Flow-sorted breast tumor (br) normal samples were assayed in triplicate (some curves are superimposed). (A and B) Total RNA ( $50 \mathrm{ng} / \mu \mathrm{L}$ and $50 \mathrm{pg} / \mu \mathrm{L})$ from unsorted fresh A549 cells and (C) total RNA $(50 \mathrm{ng} / \mu \mathrm{L}$ and $50 \mathrm{pg} / \mu \mathrm{L})$ from hTERTtransfected human keratinocytes were used as controls and appear in triplicate to the left and the right of the breast tumor tracings. 


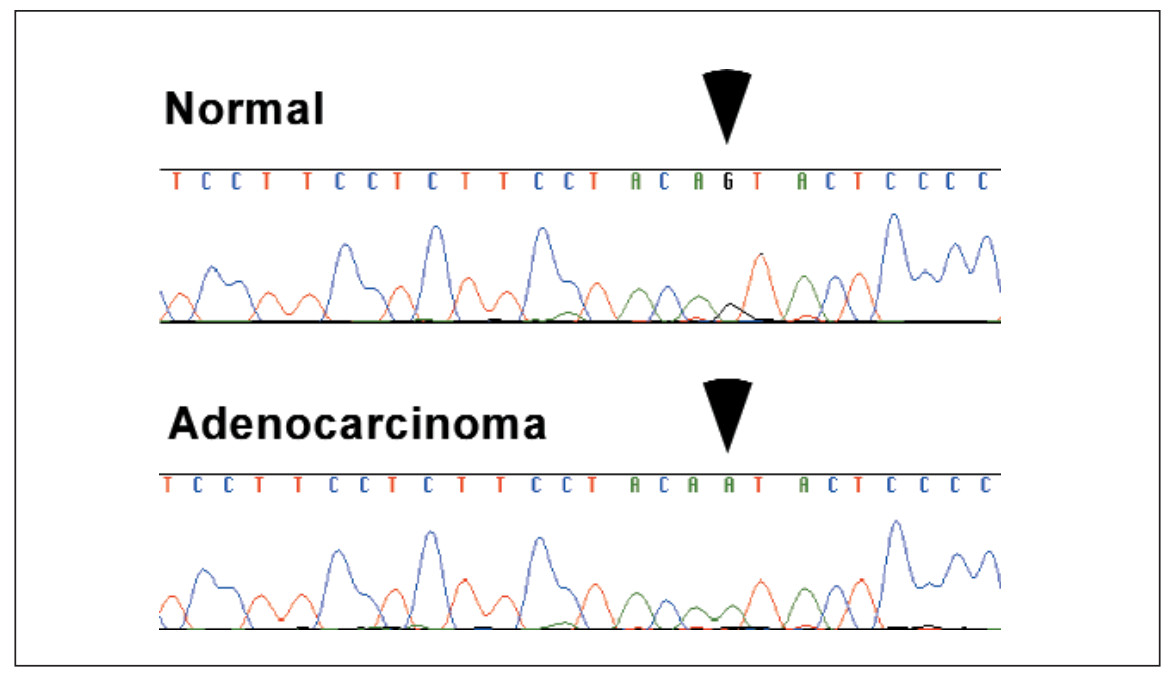

Figure 4. TP53 sequence analysis of genomic DNA isolated from whole-cell sorted cytokeratin-positive breast epithelial cells. A somatic mutation $(\mathrm{G} \rightarrow \mathrm{A}-5$ splice acceptor site exon 5$)$ was detected in aneuploid epithelial cells sorted from a breast tumor biopsy.

quencing (Figure 4).

We have previously shown that DNA content and multiparameter DNA content/Ki-67 analysis provide highly objective markers of neoplastic progression and can be used to purify nuclei from neoplastic cell populations. These assays have provided the means for extensive genotyping of complex human neoplastic cell lineages in vivo $(1,10)$ but have not allowed the analysis of expression. Whole epithelial cells prepared as described earlier can be sorted at rates of $2-20 \times 10^{3} / \mathrm{s}$ (depending on the instrument model) and provide both high-quality RNA and DNA. This material was suitable for wholegenome amplification, genotyping, and sequencing and can therefore be used to investigate the relationships between expression patterns and objective genetic markers of neoplastic progression, such as TP53 mutations and nonrandom loss of heterozygosity in clonal cell populations. The ability to efficiently flow sort populations of whole epithelial cells will permit comprehensive gene expression and genotyping analyses of well-defined clonal populations in studies of human neoplasia.

\section{ACKNOWLEDGMENT}

This report was supported by National Institutes of Health grant no. RO1CA78855.

\section{REFERENCES}

1.Barrett, M.T., C.A. Sanchez, L.J. Prevo, D.J. Wong, P.C. Galipeau, T.G. Paulson, P.S. Rabinovitch, and B.J. Reid. 1999. Evolution of neoplastic cell lineages in Barrett oesophagus. Nat. Genet. 22:106-109.

2.Church, J.G., E.A. Stapleton, and B.D. Reilly. 1993. Isolation of high quality mRNA from a discrete cell cycle population identified using a nonvital dye and fluorescence activated sorting. Cytometry 14:271-275.

3.Deng, G., Y. Lu, G. Zlotnikov, A.D. Thor, and H.S. Smith. 1996. Loss of heterozygosity in normal tissue adjacent to breast carcinomas. Science 274:2057-2059.

4.Dunne, J.F., J. Thomas, and S. Lee. 1989. Detection of mRNA in flow-sorted cells. Cytometry 10:199-204.

5.Esser, C., C. Gottlinger, J. Kremer, C. Hundeiker, and A. Radbruch. 1995. Isolation of full-size mRNA from ethanol-fixed cells after cellular immunofluorescence staining and fluorescence-activated cell sorting (FACS). Cytometry 21:382-386.

6.Galipeau, P.C., L.J. Prevo, C.A. Sanchez, G.M. Longton, and B.J. Reid. 1999. Clonal expansion and loss of heterozygosity at chromosomes $9 \mathrm{p}$ and $17 \mathrm{p}$ in premalignant esophageal (Barrett's) tissue. J. Natl. Cancer Inst. 91:2087-2095.

7.Khochbin, S., D. Grunwald, M. Pabion, and J.J. Lawrence. 1990. Recovery of RNA from flow-sorted fixed cells. Cytometry 11:869-874.

8.Longley, J., T.G. Ding, C. Cuono, F. Durden, C. Crooks, S. Hufeisen, R. Eckert, and G.S. Wood. 1991. Isolation, detection, and amplification of intact mRNA from dermatome strips, epidermal sheets, and sorted epidermal cells. J. Invest. Dermatol. 97:974-979.

9.Maitra, A., Wistuba, II, A.K. Virmani, M. Sakaguchi, I. Park, A. Stucky, S. Milchgrub, D. Gibbons et al. Enrichment of epithelial cells for molecular studies. Nat. Med. 5:459-463.

10.Mei, R., P.C. Galipeau, C. Prass, A. Berno,
G. Ghandour, N. Patil, R.K. Wolff, M.S. Chee et al. 2000.Genome-wide detection of allelic imbalance using human SNPs and highdensity DNA arrays. Genome Res. 10:11261137.

11.Nature Genetics. 1999. The Chipping Forecast. Nat. Genet. 21(supplement 1).

12.Paulson, T.G., P.C. Galipeau, and B.J. Reid. 1999. Loss of heterozygosity analysis using whole genome amplification, cell sorting, and fluorescence-based PCR. Genome Res. 9:482491.

13.Prevo, L.J., C.A. Sanchez, P.C. Galipeau, and B.J. Reid. 1999. p53-mutant clones and field effects in Barrett's esophagus. Cancer Res. 59:4784-4787.

Received 3 August 2001; accepted 20 November 2001.

Address correspondence to:

Dr. Peter S. Rabinovitch

Department of Pathology

University of Washington

Seattle, WA 98195, USA

e-mail:peterr@medicine.washington.edu

For reprints of this or
any other article, contact
Reprints@BioTechniques.com

